\title{
LAS MINAS PREHISTÓRICAS DE GAVÁ (BARCELONA): UN EJEMPLO DE ESTUDIO, CONSERVACIÓN Y PRESENTACIÓN PÚBLICA DE UN YACIMIENTO ARQUEOLÓGICO
}

\author{
THE PREHISTORIC MINES OF GAVÀ (BARCELONA): AN EXAMPLE \\ OF A COMPREHENSIVE APPROACH TO THE STUDY AND PUBLIC PRESENTATION \\ OF AN ARCHAEOLOGICAL SITE
}

MÒNICA BLASCO (*)

MÒNICA BORRELL $(*)$

JOSEP BOSCH $(*)$

\section{RESUMEN}

Las Minas Prehistóricas de Gavá proporcionaron variscita, un material ornamental, hace 6000 años. Desde hace diez años el Museo de Gavá impulsa una intervención integral (investigación, conservación y difusión), financiada por diversas instituciones (Ayuntamiento, Generalitat de Cataluña, Diputación de Barcelona e INEM), lidera y coordina un equipo interdisciplinar y mantiene convenios de colaboración con diferentes universidades. Las minas están abiertas al público desde 1993 y adecuadas para que la seguridad, movilidad y comprensión de los visitantes, no afecten su conservación y el rigor científico. Las visitas son guiadas, centradas en experimentar emociones y vivencias. Aunque se dirigen a un público amplio, los escolares forman el grupo más numeroso, con una oferta específica. Son un recurso didáctico aceptado en escuelas de Barcelona y su área metropolitana. El principal proyecto futuro es el Parque Arqueológico de las Minas Prehistóricas, centro de interpretación del Neolítico y del origen de la minería, que persigue la continuidad de la intervención y atraer al turismo cultural de la ciudad de Barcelona.

\footnotetext{
ABSTRACT

The Prehistoric Mines of Gavà used to provide variscite about 6000 years ago. This mineral was used for decora-

(*) Museu de Gavà. Plaça de Dolors Clua 13-14. 08850 Gavà. Correo electrónico: museu.gava@bcn.servicom.es

El artículo fue remitido en su versión final el 3-X-2000.
}

tive purposes. For the last ten years, the Gavà Museum has been implementing a comprehensive intervention (research, conservation and information dissemination) campaign for the mines. This programme is financed by many different institutions, such as the city hall, the Generalitat de Cataluña (the Catalan Government), the Diputación de Barcelona (the city council) and INEM (employment office). The museum leads and coordinates an interdisciplinary team and has established cooperation agreements with some universities. The Prehistoric Mines can be visited since 1993, and meet the visitors'safety, mobility and understanding requirements, without affecting their conservation and scientific rigor. Visits are guided and their goal is to make people experience emotions. Although they have got a varied target group, they are especially aimed at students. Thus, there is a number of activities planned only for them. The visits to the Prehistoric Mines have been considered an accepted educational resource in Barcelona and its metropolitan area. The main future project of the museum is the Archaeological Park of the Prehistoric Mines. It will be a centre aimed at interpreting the Neolithic period and the origin of the mining industry. Its objectives are to maintain intervention and to attract the cultural tourism in Barcelona.

Palabras clave: Minas Prehistóricas. Neolítico. Presentación museográfica. Didáctica. Parque arqueológico. Turismo cultural.

Key words: Prehistoric Mines. Neolithic. Museographic presentation. Educational.Archaeological park. Cultural tourism. 


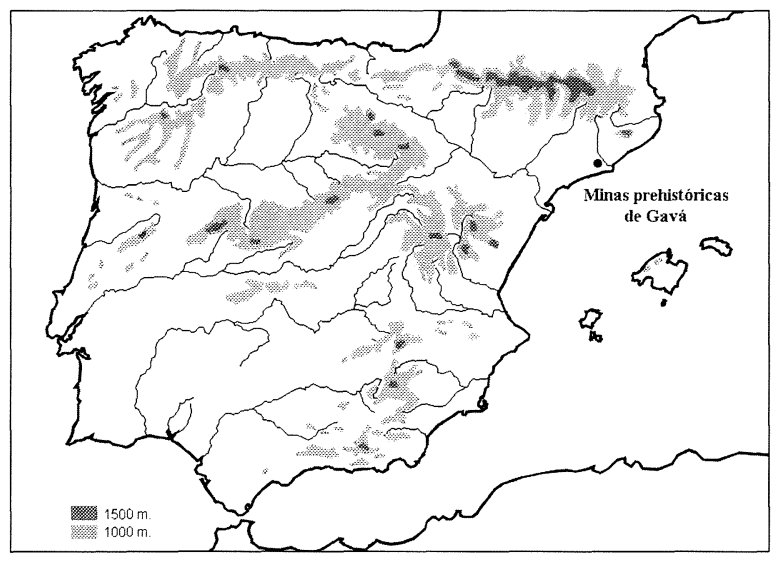

Fig. 1. Situación del yacimiento arqueológico de las Minas Prehistóricas de Gavá (Barcelona).

\section{DESCRIPCIÓN DEL YACIMIENTO Y SU ENTORNO}

El descubrimiento de las Minas Prehistóricas de Gavá (Fig. 1) se produjo en la década de los años setenta con el inicio de la urbanización del sector norte de la población de Gavá, en el barrio conocido como CanTintorer. Algunas de las edificaciones que se levantaron destruyeron parte del conjunto minero, aunque permitieron su identificación como yacimiento arqueológico. El yacimiento es muy extenso y, si bien en parte está en zona forestal, es en este sector de Can Tintorer donde se hallan la mayoría de las minas conocidas hasta el momento. Su explotación se inició hace unos 6000 años, al final del Neolítico antiguo evolucionado postcardial (la datación radiocarbónica más antigua obtenida es $5350 \pm 190 \mathrm{BP}$ ), se desarrolló durante todo el Neolítico medio, cesó al final de este periodo y en total duró unos 800 años. Las minas de Gavá se sitúan, por tanto, entre las evidencias más antiguas de minería subterránea y pueden considerarse, por el momento, el complejo minero con galerías más antiguo de Europa.

De las minas se extraía sobre todo variscita y en menor grado turquesa, minerales de coloración más o menos verdosa que se conocen también con el nombre genérico de calaíta. Ambos son del grupo de los fosfatos, el primero de aluminio y el segundo de aluminio y cobre, y se localizan entre pizarras que tienen su origen en materiales del Silúrico, periodo del Paleozoico inferior. Con la variscita de Gavá se confeccionaron única y exclusivamente adornos corporales, generalmente cuentas para collares, cuya manufactura se realizaba junto a las mismas minas, como lo indican las numerosas piezas abandonadas durante su proceso de elaboración y algunos de los instrumentos utilizados en dicho proceso, como pulidores de arenisca para dar forma a las piezas y taladros obtenidos a partir de pequeñas laminitas de sílex.

La evolución geológica de la zona hizo que las pizarras se dispusieran muy inclinadas, lo mismo que las mineralizaciones contenidas en ellas, entre las que estaban la variscita y la turquesa, distribuidas en estratos o niveles, por un lado, y en filones o vetas, por otro. Los primeros siguen la dirección de las capas de pizarra, con una orientación entre O-E y NO-SE, mientras que los segundos las atraviesan perpendicularmente, con orientaciones entre N-S y NE-SO. Estos materiales fueron cubiertos por niveles de caliches y de arcillas a principios del Cuaternario. La morfología y distribución de las estructuras mineras del Neolítico se adaptaron a esta geología. Pozos más o menos verticales atravesaban las capas estériles de arcilla y de caliche hasta la pizarra, donde se encontraban los minerales, y en este punto se realizaban amplias cámaras y galerías. Las primeras seguían las orientaciones de los minerales en estratos y las segundas las de los filones, de menor grosor y abundancia. Esto explica las direcciones sistemáticas de las cámaras y galerías que interconectadas entre sí forman una red que podemos considerar prácticamente ortogonal, con irregularidades debidas a la excavación y a la estabilidad de las mismas pizarras. Abiertas en diferente pisos, siguen la inclinación de las capas de roca y de los minerales y actualmente superan los $11 \mathrm{~m}$ de profundidad. Se conocen unas setenta bocas de mina, el recorrido más largo explorado hasta hoy es de unos $45 \mathrm{~m}$ y la sala más grande tiene unos $7 \mathrm{~m}$ de altura con una superficie de unos $16 \mathrm{~m}^{2}$. No obstante, probablemente haya recorridos y salas más grandes que todavía no han sido descubiertos.

En aquellos lugares donde la extracción de mineral había finalizado, las cavidades fueron rellenadas con materiales de desecho producidos por la abertura y explotación de nuevas cavidades, principalmente bloques de esquisto fragmentados entre los cuales se encuentran herramientas mineras rotas o muy gastadas que habían dejado de ser útiles. Con las excavaciones arqueológicas se han podido recuperar los restos de picos o mazas hechos de corneana, percutores de cuarcita y cinceles de

T. P., 57, n. $^{\circ} 2,2000$ 
hueso de buey. Por otro lado, algunos pozos de acceso a las minas, una vez abandonados, fueron utilizados como basureros de los desechos producidos por la vida doméstica o también, en ocasiones, se aprovecharon como lugares sepulcrales. La excavación de estos sedimentos proporciona mucha información sobre la vida de las comunidades que explotaron las minas, sobre sus formas de subsistencia, su tecnología, la organización social, las creencias y rituales, así como sobre el paleoambiente de la época.

Se ha documentado el cultivo de diferentes tipos de cereal, la ganadería de ovejas, cabras, bueyes y cerdos, base de la subsistencia complementada con la caza, la recolección y una pesca selectiva de determinadas especies que debía permitir diversificar la dieta del grupo. Sabemos también que mientras duró la ocupación neolítica en Gavá hubo importantes cambios en el paisaje del entorno inmediato del asentamiento, buena parte de ellos causados por la acción humana que provocó deforestaciones, extensión de comunidades vegetales secundarias y de cultivos cerealistas. Éstos debieron ocupar, amplias superficies junto con los pastizales; los bosques de encinas y robles quedaron reducidos a las hondonadas y las umbrías; había pequeños bosques de ribera junto a las aguas superficiales interiores, pinares con arbustos sobre los suelos arenosos del sector litoral y, por último, maquia y maleza con algunos pinos dispersos en el resto del territorio.

Las piezas de variscita elaboradas en Gavá tuvieron una distribución y dispersión considerable entre las poblaciones del Neolítico medio de la actual Cataluña. Se han encontrado diversas piezas en ajuares funerarios en yacimientos de la zona central y prelitoral sobre todo, pero también en un yacimiento de Andorra que, al parecer, constituye el lugar más alejado donde hasta el momento se ha documentado variscita de Gavá. La dispersión de este mineral, la envergadura del yacimiento minero y la dificultad y complejidad que debía suponer explotarlo con las tecnologías propias del Neolítico, teniendo en cuenta además que sólo servía para confeccionar objetos suntuarios, son factores que permiten plantear diversas hipótesis sobre la función social de los objetos hechos de variscita, que tenía que ser considerada como un elemento de gran valor, probablemente con importantes y diversas connotaciones de índole simbólica, religiosa, económica o de diferenciación social.

\section{LA PUESTA EN VALOR DEL YACIMIENTO: HISTORIA DEL PROYECTO Y CRITERIOS PRINCIPALES}

Desde la creación del Museo de Gavá en 1978, las Minas Prehistóricas han sido el núcleo principal de la actividad de esta institución, que desde entonces se dedica a su investigación sistemática y puesta en valor. Las primeras intervenciones en el yacimiento tuvieron como finalidad la excavación y la investigación arqueológicas así como la divulgación de los resultados sobre todo entre la comunidad científica. Sin embargo, en 1990 se produce un replanteamiento de los objetivos y de la envergadura de las intervenciones y se pone en marcha un proceso que tiene como misión principal la dinamización del conjunto. Se contempla la potenciación de la investigación, la ejecución de un programa de conservación preventiva y de consolidación y restauración de las estructuras, una estrategia de difusión a amplios sectores de la sociedad y, en general, la gestión de los medios disponibles para obtener una mayor rentabilidad social del yacimiento. Este cambio representa la superación de una concepción exclusivamente científica para incorporar e integrar otras líneas de actuación que proporcionan al proyecto mayor riqueza conceptual.

El Museo de Gavá, organismo autónomo de carácter municipal, desarrolla desde entonces el proyecto de intervención integral en las Minas Prehistóricas que se estructura a partir de tres pilares esenciales que son la investigación, la conservación y la difusión, de manera que se puede seguir todo el proceso, desde la producción del conocimiento científico hasta su transmisión a diversos sectores y colectivos de la sociedad. A causa de la complejidad del yacimiento y la envergadura del proyecto, el Museo de Gavá ha promovido la participación e integración de diversos investigadores y profesionales que estudian el complejo minero desde la óptica de distintas disciplinas. Así se ha constituido un equipo interdisciplinar compuesto por arqueólogos, ingenieros de minas, geólogos, museólogos, arquitectos, botánicos, zoólogos y palinólogos esencialmente y se han establecido convenios de colaboración con distintos equipos y universidades. Dadas las características tan particulares del yacimiento, es especialmente importante la colaboración con geólogos e ingenieros de minas, tanto por cuestiones de seguridad y conservación preventiva de las estructuras mineras como para la comprensión del propio yacimiento, por lo 
cual existen convenios estables de colaboración con la Facultad de Geología de la Universidad de Barcelona y con la Escuela Universitaria de Ingeniería de Minas de Manresa, de la Universidad Politécnica de Cataluña.

Asimismo, diversas administraciones participan en el proyecto destinando recursos importantes. $\mathrm{La}$ financiación principal corre a cargo del Ayuntamiento de Gavá que sustenta el Museo, sus infraestructuras y el equipo de profesionales que diseñan, dirigen y ejecutan los programas de investigación, conservación y difusión en el yacimiento. Se cuenta también con la financiación de la Generalitat de Catalunya, especialmente destinada a la investigación y a las campañas de consolidación y también con la de la Diputación de Barcelona, que colabora sobre todo en la realización de diversas actividades de divulgación. El Museo de Gavá lidera el proyecto y desarrolla por tanto un papel de coordinación entre todos los agentes participantes, administraciones, instituciones diversas y profesionales.

Haciendo un poco de historia, el impulso inicial del proyecto lo proporcionó el Ministerio de Trabajo, a través del INEM, al conceder en 1991 una escuela taller al Ayuntamiento de Gavá dedicada a formar auxiliares de excavación y difusión del patrimonio. En el marco de la escuela taller se prospectó intensiva y exhaustivamente el yacimiento minero, se excavaron diversas minas actualmente integradas en el recorrido de la visita pública y se fijaron las bases del proyecto de difusión con la elaboración, junto con los técnicos del Museo, de diversos talleres didácticos y de los guiones de distintas modalidades de visita, que representaron el embrión de la oferta pedagógica actual del Museo de Gavá en relación a las Minas Prehistóricas. Durante los tres años que duró la escuela, los alumnos y profesores del módulo de difusión realizaron las visitas guiadas. Finalizada la experiencia, el Museo ha externalizado, a través de una concesión administrativa, los servicios de visitas y talleres, así como la gestión de una pequeña tienda que se halla en el yacimiento. Una empresa de servicios culturales surgida de la propia escuela taller asume actualmente estos servicios.

El año 1993 se pudo abrir una parte del yacimiento al público y se musealizó el solar, de propiedad municipal, donde hay la concentración mayor de minas conocidas hasta el momento (Lám. I). Es también en este sector donde se desarrollan la mayoría de actividades relacionadas con la visita pú-

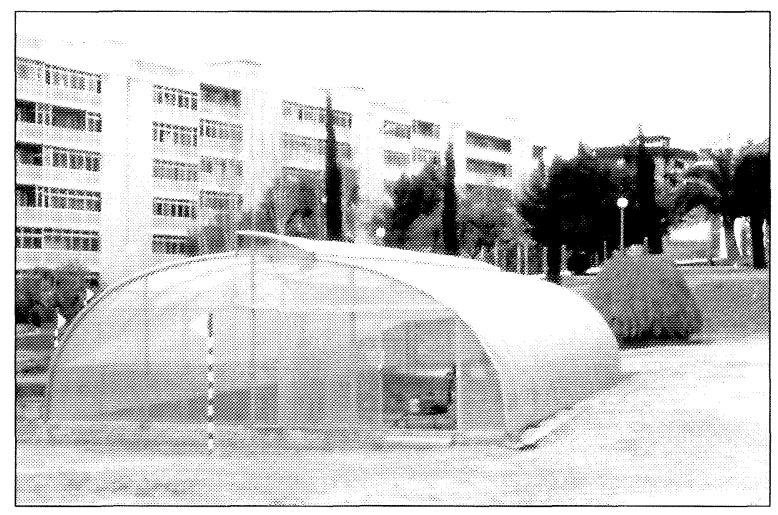

Lám. I. Vista general de la adecuación del yacimiento arqueológico de las Minas Prehistóricas de Gavá, Barcelona.

blica, donde se ejecuta el programa de consolidación y también donde se concentran las campañas de excavación y las tareas relacionadas con la investigación científica. Actualmente se dispone de una serie de equipamientos provisionales para la acogida y atención de los visitantes y para el desarrollo de las actividades didácticas: la recepción, con la venta de entradas, la tienda, los servicios y los vestuarios, una carpa-aula didáctica y área de experimentación, la reproducción de una cabaña neolítica y una pequeña exposición permanente donde se presentan resumidamente aspectos domésticos y funerarios de la comunidad minera de Gavá.

Desde 1993 el número de visitantes se ha estabilizado alrededor de las 16000 personas al año y las modalidades de servicios y actividades no han parado de crecer. Sin embargo, la apertura al público de las minas tiene que entenderse como una presentación provisional, útil para dar a conocer su importancia y poner en evidencia sus potencialidades futuras pero claramente insuficientes dadas las posibilidades, todavía no explotadas, de proyección científica, didáctica y turística del yacimiento.

Finalizada la escuela taller y con el yacimiento abierto al público, la dinamización de la Minas Prehistóricas sigue siendo el proyecto principal del Museo de Gavá y el próximo reto lo constituye la futura construcción de un parque arqueológico, actualmente en fase de redacción y de búsqueda de financiación. Las instituciones promotoras, el Ayuntamiento de Gavá y el Museo, entienden que las inversiones en patrimonio histórico generan una serie de recursos sociales, culturales, científicos e incluso económicos nada despreciables. Es difícil cuantificar los beneficios económicos que puede proporcionar, pero es indiscutible la repercusión 
directa sobre la calidad de vida de los ciudadanos y, por tanto, es apreciable su rentabilidad cultural y social.Además, la excepcionalidad del yacimiento de las Minas Prehistóricas y su condición de unicum justifican plenamente la inversión y el empeño en el desarrollo de la investigación científica, en la mejora de las condiciones de conservación del yacimiento y en la mejora de su presentación pública.

Después de más de veinte años de investigación, el conocimiento generado y la bibliografía existente son importantes (Villalba et alii, 1986; Bosch y Estrada 1994a; Bosch et alii, 1996; Villalba y Edo, 1992, entre otros), de manera que el complejo minero de Gavá es un punto de referencia obligado del Neolítico meridional europeo y se considera uno de los grandes yacimientos arqueológicos de este período. Como se ha dicho, las minas de Gavá tienen un antigüedad de 6000 años, son las minas en galería más antiguas de Europa y por tanto son absolutamente excepcionales. Además, constituyen el único centro de explotación de su época identificado hasta ahora dedicado a la obtención y al trabajo de un material utilizado exclusivamente con finalidades suntuarias, cosa que le confiere una relevancia especial. Por otro lado, el yacimiento proporciona gran cantidad de información para la reconstrucción histórica. Los estratos que rellenan sus galerías, pozos y salas contienen diversos materiales (cerámicas, industria lítica, industria ósea, etc.) y también vestigios botánicos y faunísticos que son relativamente abundantes y aparecen en un buen estado de conservación. Su estudio permite aproximarnos a las condiciones paleoambientales, sociales y económicas en las que se produjo el proceso de producción minera que estudiamos, aproximación necesaria para interpretar el yacimiento dentro de su contexto histórico.

Además de estas razones científicas, basadas en su valor como fuente de información sobre el pasado, existen razones de índole diferente que también justifican la puesta en valor del yacimiento. Entre éstas, destacaremos las posibilidades educativas que se desprenden de un poder de evocación de épocas pretéritas que no se encuentra entre la mayoría de los yacimientos prehistóricos. Habitualmente la comprensión de estos yacimientos presenta serias dificultades, debido a su conservación parcial y a que, por sus características intrínsecas, los elementos de conexión con la actualidad son escasos. En el caso de las minas neolíticas de Gavá, las estructuras se conservan prácticamente en su totalidad, lo que facilita su musealización y la com- prensión por parte de la mayoría del público, infantil o adulto. Por otro lado, al tratarse de galerías y pozos subterráneos, la visita tiene un valor añadido, vivencial y emocional, que vale la pena aprovechar para transmitir contenidos y valores. Las Minas Prehistóricas son un yacimiento arqueológico único por sus características y por la riqueza de información histórica que está proporcionando. $\mathrm{La}$ espectacularidad y excepcionalidad de los espacios que definen los pozos, las galerías y las salas subterráneas hacen que tenga además altas posibilidades de convertirse, en el futuro, en un lugar de obligada visita en el contexto actual de potenciación del turismo cultural en general y del área metropolitana de Barcelona en particular.

En cuanto a los criterios generales que rigen la actuación del Museo de Gavá en las Minas Prehistóricas, ya se ha mencionado que pretende ser integral y interdisciplinar. La conservación del yacimiento es un deber legal de la administración y, por tanto, también del Museo de Gavá. La investigación es el primer puntal que proporciona las bases científicas sobre las cuales se desarrolla todo programa o acción de divulgación, sea cual sea el tipo de público, y la difusión es una apuesta clara encaminada a obtener la máxima rentabilidad social del conocimiento desarrollado y de la dinamización del patrimonio histórico. Además, hay que ejecutar las tres grandes líneas de intervención -investigación, conservación y difusión- sin interferencias, han de alimentarse mutuamente $y$, en última instancia, debemos garantizar el desarrollo de todos los programas.

En relación a la conservación, dos líneas estratégicas rigen la actuación del Museo de Gavá con la finalidad de garantizar la transmisión de este bien patrimonial a las generaciones futuras. Por un lado, existe una política de protección legal de las Minas Prehistóricas dado que es un yacimiento que se halla en parte en contexto urbano y, por tanto, está sometido y afectado por la presión urbanística propia de una población del área metropolitana de Barcelona en crecimiento y expansión. Por esta causa, en 1996, la Generalitat de Cataluña declaró el complejo minero de Gavá Bé Cultural d'Interès Nacional, que es la figura que otorga mayor protección a un bien patrimonial de la legislación catalana, y más recientemente, en 1999 el Ayuntamiento de Gavá ha aprobado el Pla Especial de Protecció i Catàleg del Patrimoni Arqueològic de Gavà, que es un instrumento de gestión urbanística encaminado a proteger el subsuelo arqueológico del municipio. 
Por otro lado, en cuanto a la conservación de las estructuras mineras conocidas, se ejecutan sistemáticamente acciones de conservación preventiva de la roca y se procura mantener el microclima particular del interior de las minas que es la mejor garantía para su conservación, con controles climáticos periódicos, y también se llevan a cabo campañas de consolidación y restauración de aquellas estructuras degradadas o inestables. Para ello se utilizan procedimientos desarrollados por la minería y la ingeniería, adaptados a la singularidad y valor histórico del yacimiento. Debido a la falta de precedentes y a la poca experiencia en este tipo de trabajos ha sido necesario investigar los posibles factores degradantes de la roca, las condiciones ambientales de conservación y las medidas para mantenerlas, los procedimientos de restauración a seguir y los productos a utilizar $y$, por último, la efectividad alcanzada en cada momento (Crespo et alii,1997; Bosch, [e.p.]).

En relación a la investigación científica, el objetivo es realizar una labor diversificada y rigurosa de manera que se contribuya decisivamente al conocimiento del Neolítico en el sur de Europa. Las actuales investigaciones arqueológicas en este yacimiento pretenden estudiar el proceso de producción minera que las originó y las condiciones ambientales, económicas y sociales en las que tuvo lugar. Los principales centros de interés de estas investigaciones son la cronología y las fases culturales, la evolución del paisaje y la incidencia antrópica sobre el mismo, el aprovechamiento de los recursos económicos, el proceso de trabajo minero, el proceso de trabajo de la variscita extraída de las minas, las superestructuras social e ideológica y los motores de su evolución. Estas investigaciones se desarrollan según un programa que contempla excavaciones en el interior de determinadas minas, seleccionadas en función de los objetivos y de los centros de interés marcados, estudios geológicos en el mismo yacimiento así como en su entorno y diferentes estudios de laboratorio (ver entre otros trabajos Álvarez y Clop, 1998; Bosch y Estrada, 1994a, b; Bosch et alii, 1996; Bosch et alii, 1999; Costa et alii, 1994).

Finalmente, los resultados de las investigaciones arqueológicas se difunden por los canales habituales como congresos, artículos en revistas especializadas y ediciones monográficas del propio museo; pero también, como veremos, se procesan los resultados más relevantes y se procura incorporarlos en la explicación de la visita guiada, en la propia exposición permanente del Museo o en los materiales didácticos y publicaciones de divulgación que se confeccionan.

\section{LA ADECUACIÓN MUSEOGRÁFICA DEL YACIMIENTO DE LAS MINAS PREHISTÓRICAS DE GAVÁ}

La musealización de cualquier yacimiento arqueológico presenta unas dificultades específicas ya que se tienen que coordinar las necesidades del público (comprensión, movilidad...) y la conservación de restos y estructuras. En el caso de las Minas Prehistóricas estas dificultades se ven agravadas por las características singulares de las mismas.

El hecho de que nos encontremos ante un yacimiento subterráneo presenta un valor añadido de singularidad, espectacularidad y visita de estructuras completas; pero comporta inconvenientes importantes en cuanto a seguridad e integridad de las estrúcturas. Además en el caso de Gavá se trata de pozos, galerías y cámaras de dimensiones reducidas, recorridos relativamente cortos y, lógicamente, espacios por los que los visitantes no pueden desplazarse sin guía. El entorno urbano del yacimiento es también un elemento a tener en cuenta, ya que si por un lado facilita el acceso del público y la disponibilidad de servicios periféricos, por otro condiciona la percepción que se tiene del mismo. Por otro lado, aunque actualmente se dispone de una amplia información sobre el contexto social o económico de las comunidades que explotaron las minas en época neolítica, la falta de estructuras en superficie relacionadas con estos aspectos dificulta la comprensión del yacimiento y condiciona las estrategias de transmisión de conocimientos.

Como ya se ha apuntado anteriormente, desde el inicio del proyecto, los trabajos de adecuación del yacimiento a la visita pública se han desarrollado de forma coordinada con los trabajos de investigación y conservación. En la mayoría de casos la musealización se ha supeditado a excavación y conservación, mientras que en otros la presentación al público ha sido el motivo de intervenciones, especialmente en aquellos casos en los que objetivos de unos y otros no se interfieren, sino que incluso convergen. Por último, han sido los aspectos económicos los que han acabado marcando el ritmo de la ejecución del proyecto en sus diferentes vertientes. En cualquier caso, el yacimiento de las Minas Prehistóricas es una extensión de las dependencias y de la actividad del Museo, del que no puede desvincu-

T. P., 57, n. ${ }^{\circ} 2,2000$ 
larse, y su puesta en valor ha estado marcada por la necesidad de optimizar recursos, tanto económicos como humanos o de infraestructuras.

Han sido estos diferentes aspectos los que han motivado que el yacimiento en superficie contara con el mínimo acondicionamiento (vallado, ajardinamiento, protección de pozos y estructuras mineras abiertas, zona de recepción y aula para la realización de actividades...) y musealización (señalización de accesos a estructuras mineras, recreación de una cabaña, pequeña exposición de materiales arqueológicos...).

Asimismo, aun contando con limitaciones en la presentación de las estructuras mineras, se optó por reforzar la vía emocional y vivencial en la visita a las minas. En este sentido, se acondicionó una de las minas que, por su estructura y el punto en que se encontraba la investigación arqueológica, presentaba una estructura de explotación representativa, tenía el recorrido más largo y menos dificultades para la adecuación a la visita. Así, la intervención arqueológica en zonas puntuales y la instalación de iluminación, escaleras y pasarelas en los puntos de más difícil tránsito, fueron suficientes para su apertura a la visita de un público ya amplio. Pero la dificultad de efectuar musealizaciones similares en otras minas no fue inconveniente para ofrecer al público la posibilidad de realizar un recorrido subterráneo más amplio. La llamada visita aventura permite a los visitantes más ágiles e intrépidos la posibilidad de recorrer galerías y pozos sin iluminar y de un diámetro que en algunos puntos obliga a arrastrarse, sin afectar la correcta conservación de las estructuras.

Dadas las características del yacimiento y los condicionantes económicos del proyecto inicial, se optó por potenciar la información personal por encima de otros recursos de comunicación. Las visitas se realizan siempre en compañía de guías y el recorrido subterráneo en grupos reducidos de máximo diez personas, mientras que la visita aventura se realiza en grupos máximo de cinco personas (Lám. II).

Asimismo, la existencia de la exposición permanente del Museo hizo que se reservase la muestra de materiales arqueológicos a estas salas, por otro lado, mejor dotadas en cuanto a infraestructura y seguridad. En este sentido, la visita a las Minas Prehistóricas no se puede desvincular de la visita a la exposición permanente del Museo, en la que, siguiendo el hilo conductor "La formación y transformación del paisaje", se realiza una aproximación al entorno natural y cultural de Gavá y su comarca.

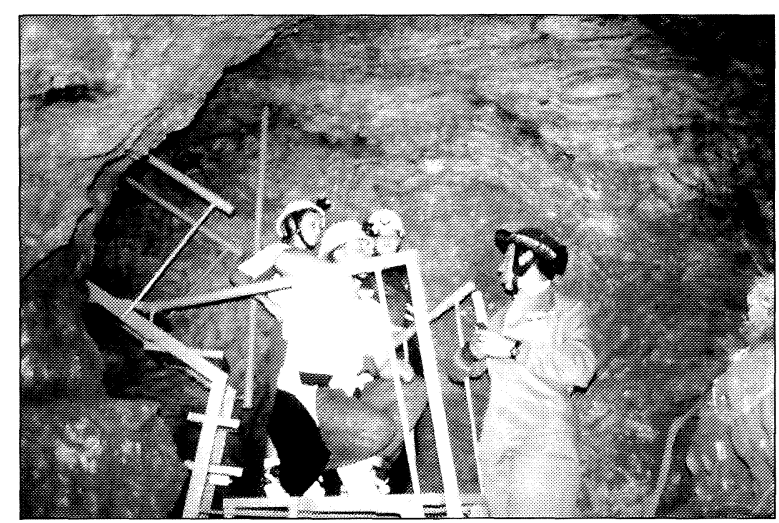

Lám. II. Grupo de visitantes con guía en el interior de las minas neolíticas de Gavá adecuada para el público.

Partiendo de la formación geológica de la zona -con el macizo del Garraf y el delta del río Llobregat como elementos singulares-, se hace un repaso a la relación entre el paisaje y el ser humano a lo largo de la historia. En este recorrido diacrónico, destacan tres etapas: el Neolítico, con el ejemplo de las Minas Prehistóricas, las etapas ibérica y romana, y la industrialización. El audiovisual "Las voces del paisaje" sirve de presentación e introducción a la exposición.

\section{LA CAPTACIÓN Y LA ATENCIÓN AL PÚBLICO}

Teniendo en cuenta los criterios seguidos en la puesta en valor de las Minas Prehistóricas, los destinatarios a los que nos dirigimos son amplios sectores de público diferentes. Como ya se ha dicho anteriormente, el Museo da a conocer los resultados de las investigaciones en el ámbito científico, pero la divulgación que se realiza presta especial atención al gran público y se apoya en la exposición permanente, la visita al yacimiento y programas de actividades complementarias.

Por un lado podemos destacar el público de fin de semana: público especialmente familiar, con un interés cultural y procedente en su mayoría del área metropolitana de Barcelona y comarcas próximas, al que, además de la visita a las Minas, el primer domingo de mes se le ofrece participar en actividades de experimentación y de iniciación a temas referentes al patrimonio natural y cultural. Difícilmente se puede hablar de turistas, ya que la promoción de las minas no se realiza en este ámbito, no se dirige a grandes grupos, ni hay una publicidad fuera 


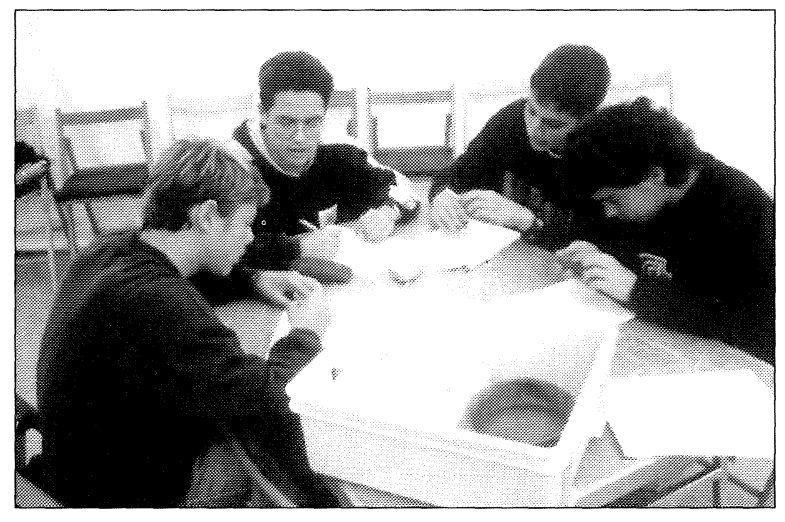

Lám. III.Visitantes escolares realizando un taller en las instalaciones de las Minas Prehistóricas de Gavá, Barcelona.

del ámbito catalán. Las características de la visita a las Minas -con limitaciones para absorber grupos numerosos y un acceso no practicable para la totalidad de la población-, no hace viable actualmente la captación de grandes grupos ni de turismo de tercera edad, por ejemplo. Aún así, la proximidad de Barcelona permitiría, en un futuro, atraer turistas hacia el yacimiento.

Actualmente el Museo está trabajando con el objetivo de incluir las minas dentro de rutas de turismo especializado con interés en patrimonio cultural, minería, etc. En este sentido, desde el año pasado, el Museo cuenta con la colaboración de la Agencia de Promoción Turística de la Diputación de Barcelona para dar a conocer el potencial turístico del yacimiento. Bajo sus auspicios se ha puesto en marcha el programa Barcelona Turismo Industrial que tiene como misión específica dar a conocer el patrimonio cultural relacionado con la tecnología y el trabajo. En este ámbito se ha constituido un grupo de trabajo para desarrollar productos turísticos estrictamente relacionados con el mundo de la minería.

El público escolar es cuantitativamente el más importante usuario de la visita a las Minas Prehistóricas (Lám. III). Los esfuerzos realizados por el Museo se dirigen a escolares desde niveles de educación infantil hasta bachillerato, sin olvidar estudiantes universitarios o recién licenciados que pueden completar su formación participando en el "Curso de Arqueología de Gavá", de carácter anual y monográfico y en el que se combina la experimentación y las clases teóricas.

La aplicación de la Reforma Educativa ha comportado que en el curriculum escolar de educación primaria y secundaria hayan adquirido una mayor importancia los contenidos referentes al conocimiento del entorno, tanto natural como social y cultural, y, dentro de éstos, los contenidos que hacen referencia a la adquisición de procedimientos, de hábitos y actitudes por parte de los alumnos. Es en este contexto que el Museo, que tiene la obligación de difundir el conocimiento del patrimonio, dedica grandes esfuerzos para satisfacer las demandas de este colectivo, permitiendo su acceso al conocimiento de este entorno más próximo -tanto arqueológico como histórico o natural-; y proporcionándole herramientas para que chicos y chicas consigan los objetivos que tienen marcados. Por otro lado, acercándolos a la realidad más próxima, queremos colaborar para que sean mejores ciudadanos en el futuro.

Lógicamente, el público escolar necesita una adecuación específica tanto de los contenidos como de los servicios que se ofrecen, además de una articulación concreta de la visita para poder atender a los ǵrupos. Actualmente, el Museo tiene una oferta global de cerca de treinta actividades educativas tanto del ámbito de las ciencias naturales como sociales que se realizan en el Museo, en visitas e itinerarios externos o en el mismo yacimiento de las Minas. Como el Museo pretende ser una instrumento al servicio de los estudiantes, todas las actividades están relacionadas con el curriculum, se basan en la experimentación y participación por parte del alumno, y se intenta siempre establecer un contacto con el entorno que sea participativo y vivencial.

Otro colectivo importante al que nos dirigimos es el de los grupos de ocio infantiles y juveniles, que han incrementado -más en períodos vacacionales que de fin de semana-, su presencia y demanda de actividades que combinen el entretenimiento con la cultura. Para estos grupos, además de la visita a las minas se organizan actividades y talleres en los que se potencia los aspectos lúdicos sin olvidar nunca la transmisión de unos contenidos culturales y de respeto al patrimonio.

A partir de los cómputos anuales de visitantes desde 1995, podemos decir que el yacimiento ha llegado a una estabilización alrededor de los 16000 visitantes al año (cabe tener en cuenta que el yacimiento fue abierto a la visita pública en el mes de octubre del año 1993 y que ya en el año 1994 recibió 13924 visitas). En 1999 el $75 \%$ de visitas correspondieron a grupos de centros escolares o grupos infantiles organizados, mientras que el $18 \%$ fueron visitas generales y el $7 \%$ restante, visitas aventura, valores que están de acuerdo con las ca-

T. P., 57, n. $^{\circ} 2,2000$ 
racterísticas de cada uno de los tipos de visita (días en que se realizan, número de personas por grupo...) y que son extrapolables a años anteriores. En cuanto a los grupos de edad, el más numeroso, coincidiendo con los datos anteriores, es el de menores de 14 años $(69 \%)$-grupos infantiles organizados, grupos de educación primaria y primeros cursos de educación secundaria-; seguido del grupo con edades comprendidas entre los 25 y 44 años (15\%). Lógicamente, dadas las características del yacimiento, el grupo menos representado es el de mayores de 65 años (3\%). Las minas son, por tanto, un recurso didáctico consolidado que tiene considerable aceptación especialmente en centros escolares de Barcelona y área metropolitana en general. En relación a la distribución de los visitantes por meses, los números reafirman esta última consideración de recurso escolar importante, y reflejan también el hecho de que las Minas Prehistóricas están actualmente fuera de los circuitos turísticos, ya que son los meses de agosto, septiembre, enero y diciembre -coincidiendo con períodos vacacionales-los que menos visitantes recibe el yacimiento.

La inversión directa en publicidad que realiza el Museo con el objetivo de llegar a cada uno de los diferentes públicos es reducida, y los mecanismos a los que se recurre con más frecuencia son indirectos y puntuales en el tiempo. Encuestas realizadas entre los visitantes de las minas ponen de manifiesto que el medio de promoción más eficaz es la prensa escrita, en la que cabe distinguir la contratación de espacios publicitarios y la generación de noticias a partir de la actividad cotidiana del Museo. La recomendación personal queda ya en un segundo término respecto a los medios escritos, aunque tendría su importancia dada la escasa inversión económica realizada, tal como se ha dicho, en publicidad. Otro mecanismo que se descubre relativamente eficaz es el de las promociones concertadas con entidades o colectivos específicos como el Club Súper 3-club juvenil promovido por Televisió de Catalunya-, y el Reial Automòbil Club de Catalunya, cuyos miembros y usuarios de la tarjeta RACC Master tienen descuentos en los diferentes tipos de visita.

Por último, la repercusión de los canales de promoción turística se descubren parcialmente eficaces, aunque en este ámbito el Museo no concentra sus esfuerzos. Habitualmente se distribuyen folletos en oficinas de turismo de Barcelona y poblaciones turísticas cercanas, y se intenta participar en salones y ferias sectoriales. Como se ha dicho, la
Agencia de Promoción Turística de la Diputación de Barcelona es unà importante aliada, dando soporte tanto para la promoción de productos turísticos (edición del catálogo, asistencia a ferias de turismo...), como en la creación de los mismos.

Para llegar a colectivos específicos, el Museo cuenta con canales de promoción diferentes. Este sería el caso del público escolar. La presencia de las Minas en el ámbito educativo se podría diferenciar en dos aspectos. El primero es la inclusión de las Minas en los libros de texto, de manera que se convierten en un punto de referencia para el profesorado. Lógicamente no es suficiente ni el único.Anualmente, alrededor de 1500 centros educativos de Catalunya reciben la Guia i serveis del Museu i les Mines Prehistòriques de Gavà. Esta promoción se refuerza en situaciones puntuales, como cursos de verano, salones monográficos, etc... La publicidad dirigida a centros de ocio juvenil o entidades culturales también se realiza de forma directa a través de correo para cada una de las campañas anuales.

\section{PROYECTOS DE FUTURO}

Dada la satisfacción que existe por el desarrollo del proyecto en todas sus vertientes, de la respuesta del público, de la proyección científica y de la rentabilidad social que en general proporciona el yacimiento, el Ayuntamiento de Gavá, a través de su Museo, está proyectando construir el ParqueArqueológico de las Minas Prehistóricas, que será un equipamiento cultural de más de $4000 \mathrm{~m}^{2}$, un centro de interpretación sobre el Neolítico y sobre el origen de la minería en Europa que contará, además de la propia visita, con gran cantidad de servicios y actividades entorno a la puesta en valor de un yacimiento arqueológico de primera magnitud. Actualmente se están redactando los diversos proyectos y estudios previos necesarios y se está buscando la financiación que tiene que posibilitar su construcción.

El objetivo primordial es, pues, la puesta en valor de uno de los conjuntos patrimoniales más importantes y singulares de nuestro país y supondrá, de hecho, la culminación de un largo proceso de tratamiento integral del patrimonio que viene desarrollándose esencialmente desde 1990. Su construcción tiene que asegurar la continuidad del proyecto de investigación así como del programa de consolidación para garantizar el legado a las generaciones futuras, $y$ ha de permitir hacer una difusión 
amplia, ordenada y controlada de este bien patrimonial a distintos sectores de la sociedad. Implicará ofrecer también un generoso catálogo de servicios y actividades adecuadas a diversos tipos de usuarios $\mathrm{y}$, en definitiva, aumentar la rentabilidad social del yacimiento.

La fórmula cultural escogida es la construcción de un centro de interpretación sobre el Neolítico, en el cual destacará todo aquello que haga referencia a la minería prehistórica y a las minas con galerías más antiguas de Europa. El parque arqueológico acercará al visitante a una atmósfera prehistórica y habrá espacios temáticos dedicados a los poblados del IV milenio, interpretaciones sobre la agricultura, la caza, la ganadería, sobre aspectos tecnológicos, sociales, religiosos, funerarios... En definitiva, dará una visión completa de la sociedad que explotó las minas de Gavá, tratada desde puntos de vista complementarios y utilizando recursos formales heterogéneos y aquellas soluciones museográficas más efectivas en cuanto a la presentación y transmisión de la información. La realización de actividades de experimentación ayudará al visitante a adquirir además un conocimiento empírico de la historia.

Por otro lado, la espectacularidad y excepcionalidad de los espacios que definen las galerías, pozos y salas del complejo minero de Gavá, así como la potencia del propio equipamiento en proyecto proporcionan a la iniciativa altas posibilidades de convertirse en un recurso singular en el contexto actual de potenciación del turismo cultural. La construcción del parque otorgará a la comarca y al entorno metropolitano un centro de atracción turística de índole cultural y de alta calidad tanto para el público local, constituido como decíamos por los 3,5 millones de habitantes de la conurbación de Barcelona, y obviamente también para el público foráneo.

La visita a conjuntos monumentales y a lugares de interés arquitectónico, histórico o natural y también a los centros museísticos constituyen elementos fundamentales para articular una oferta turística en consonancia con los gustos y las preferencias que es detectan hoy en día y que son la tendencia más clara de futuro del sector. De hecho, la visita a museos y a conjuntos patrimoniales representa la ocupación más generalizada del turismo, especialmente en las grandes ciudades. Ésta es una realidad incontestable en Europa desde hace años y es también una tendencia detectada en nuestro país, aunque con cierta timidez todavía, pero de forma clara es una realidad en Barcelona, donde las expectativas de los visitantes y el reclamo turístico principal son la cultura, la arquitectura y los museos. Justamente gracias a la proximidad de Gavá a Barcelona y a las buenas comunicaciones existentes, las Minas Prehistóricas pueden beneficiarse de la atracción turística que representa Barcelona. Los enclaves arqueológicos o patrimoniales en general del área metropolitana son susceptibles, en consecuencia, de interesar al mismo turista que visita Barcelona y a los mismos mayoristas que venden paquetes turísticos centrados en la venta de Barcelona como destino de patrimonio y cultura.

En definitiva, entendemos que el patrimonio cultural bien explotado y fundamentado en la investigación, la conservación y la difusión puede generar una serie de recursos y beneficios sociales, culturales, científicos nada despreciables. En general son beneficios de difícil cuantificación pero no hay duda que las inversiones en patrimonio histórico influyen y revierten en la calidad de vida de los habitantes de un lugar, crean valor añadido, actúan a menudo como elementos de proyección de un territorio, ayudan a vertebrar social y culturalmente una población y pueden potenciar en cierta medida la cohesión social de una comunidad. Puede generar también recursos económicos importantes, no solamente para el autofinanciamiento del equipamiento sino que además puede generar a su alrededor actividad económica indirecta relacionada con el turismo cultural susceptible de transformar la economía de un territorio.

\section{BIBLIOGRAFÍA}

Àlvarez, A. y Clop, X. (1998): “Determinación de la materia prima del utillaje minero de las minas neolíticas de Gavá (Barcelona)". En J. Bosch, X. Terradas y T. Orozco (ed.): Actes de la $2^{\mathrm{a}}$ Reunió de Treball sobre Aprovisionament de Recursos Lítics a la Prehistòria. Barcelona-Gavà 1997. Rubricatum, Revista del Museu de Gavà, 2: 145-151.

Bernabeu, J. y Orozco, T. (ed.) (1999): Actes del II Congrés del Neolític a la Península Ibèrica. València, 1999. Saguntum, extra-2.

Bosch, J. (en prensa): "Conservació de les Mines Prehistòriques de Gavà". les. Jornades d'Estudi del Patrimoni del Baix Llobregat. Cornellà de Llobregat, 1998.

Bosch, J. y Estrada, A. (1994a): "El Neolític Postcardial a les Mines Prehistòriques de Gavà (Baix Llobregat)". Rubricatum. Revista del Museu de Gavà, 0.

- (1994b): "La Venus de Gavà (Barcelona). Una aportación fundamental para el estudio de la religión neolítica del suroeste europeo". Trabajos de Prehistoria, 51, 2: $149-158$ 
Bosch, J.; Estrada, A. y Noain, M.J. (1996): "Minería neolítica en Gavà (Baix Llobregat, Barcelona)". Trabajos de Prehistoria, 53, 1: 59-71.

Bosch, J.; Estrada, A. y JuAn-Muns, N. (1999): “L'aprofitament de recursos faunístics aquàtics, marins i litorals, durant el neolític a Gavà (Baix Llobregat)". En J. Bernabeu y T. Orozco (ed.): Actes del II Congrés del Neolític a la Península Ibèrica (València, 1999). Saguntum, extra-2:77-83.

Bosch, J.; Terradas, X. y Orozco, T. (ed.) (1998): Actes de la $2^{\mathrm{a}}$ Reunió de Treball sobre Aprovisionament de Recursos Lítics a la Prehistòria (Barcelona-Gavà, 1997). Rubricatum, Revista del Museu de Gavà, 2.

Costa, F.; Camprubí, A. y Melgarejo, J.C. (1994): “Aproximación geológica a las minas neolíticas de fosfatos férrico-alumínicos de Gavà (Catalunya)". Boletín Geológico y Minero, 105-5: 18-25.

CRESPO, J.; Font, J. y Cuello, J. (1997): “Consolidación de terrenos en una mina abierta en el período Neolítico". Ingeopres: 25-30.

Villalba, M.J.; Bañolas, L.; Arenas, J. y Alonso, M. (1986): Les mines neolítiques de can Tintorer. Gavà. Excavacions 1978-1980. Departament de Cultura Generalitat de Catalunya. Barcelona.

Villalba, M.J. y Edo, M. (1992): "Aspectes sobre la mineria subterrània i la cronologia aplicada als sistemes d'explotació". 9è Col.loqui Internacional d'Arqueologia de Puigcerdà, Estat de la investigació sobre el neolitic a Catalunya (Puigcerdà i Andorra, 1991): 195199. 